\title{
Primary prevention of road traffic accident-related traumatic brain injuries in younger populations: a systematic review of helmet legislation
}

\author{
Rebecca Y. Du, BS, ${ }^{1,2}$ Melissa A. LoPresti, MD, ${ }^{1,2}$ Roxanna M. García, MD, MS, MPH, ${ }^{3,4}$ and \\ Sandi Lam, MD, MBA ${ }^{3,4}$
}

1'Division of Neurosurgery, Texas Children's Hospital, Houston; 2Department of Neurosurgery, Baylor College of Medicine, Houston, Texas; ${ }^{3}$ Division of Pediatric Neurosurgery, Ann and Robert H. Lurie Children's Hospital of Chicago; and ${ }^{4}$ Department of Neurosurgery, Northwestern University Feinberg School of Medicine, Chicago, Illinois

\begin{abstract}
OBJECTIVE Road traffic accidents are the most frequent cause of severe traumatic brain injury (TBI), particularly among young populations worldwide. Helmets are proven to prevent injuries; however, estimates of helmet compliance are low globally. Surgical/critical care management of TBI is often used to treat these injuries, but primary prevention should be recommended. A key component in promoting TBI prevention among pediatric and young populations is through helmet legislation. The authors investigated helmet policies for motorcycles and bicycles globally to provide recommendations for how related legislation may impact TBI and guide advocacy in pediatric neurosurgery.
\end{abstract}

METHODS The authors conducted a systematic review of helmet laws and/or policies by using the National Library of Medicine PubMed and SCOPUS databases. Additional articles were identified using citation searches of key publications. Abstracts from articles of all sources were read and selected for full-text review. Details of relevant full articles were extracted and analyzed for the following: bibliographic data, study aim, design and duration, study participants, intervention characteristics, and intervention effect data.

RESULTS Of 618 search results, 53 full-text articles were analyzed for recommendations. Helmet legislation is associated with increased helmet use among bicyclists and decreased road traffic accident-related head injuries and fatalities among motorcyclists and bicyclists. Laws are more effective if comprehensive and inclusive of the following: both primary riders and passengers, all age groups, all modes of transportation made safer by helmets, a proper use clause, and standardized helmet quality measures. Cultural, socioeconomic, and infrastructural circumstances are important as well, and legislation must consider enforcement mechanisms with penalties significant enough to incentivize behavioral changes, but proportional to community socioeconomic status.

CONCLUSIONS Compulsory use laws are the optimal primary intervention; however, concurrent programs to support financial access to helmets, change cultural attitudes, increase health literacy, and improve road infrastructure will augment legislative benefits. Pediatric neurosurgeons are caretakers of children suffering from TBI. Although extensive study has explored the surgical management of TBI, the authors believe that primary prevention is instrumental to improving outcomes and reducing injury. All helmet laws are not equal; based on these findings, a comprehensive, contextspecific approach is the key to success, especially in resource-limited countries.

https://thejns.org/doi/abs/10.3171/2019.10.PEDS19377

KEYWORDS traumatic brain injury; helmet; neurosurgery; public health; advocacy; pediatric; head injury; bicycle; motorcycle; trauma

$\mathrm{T}$ RAUMATIC brain injury (TBI) is the leading cause of morbidity and mortality among young people in low- and middle-income countries (LMICs), ${ }^{7}$ where the global incidence appears to be escalating the most. The most recent Global Burden of Diseases data on brain and spinal cord injury found a 3.6\% (95\% uncertainty inter- val [UI] 7.4-4.0) increase in the incidence of TBI from 1990 to 2016, with the largest increase among LMICs. ${ }^{31}$ In 2016, the global incidence and prevalence of TBI was 27,082,033 (95\% UI 24.30-30.30 million) and 55,494,674 (95\% UI 53.40-57.62 million), respectively. TBI caused 8.1 million (95\% UI 6.0-10.4 million) years of life lived

ABBREVIATIONS HICs = high-income countries; LMICs = low- and middle-income countries; $\mathrm{RCT}=$ randomized controlled trial; $\mathrm{RTA}=$ road traffic accident; TBI = traumatic brain injury; UI = uncertainty interval.

SUBMITTED June 26, 2019. ACCEPTED October 14, 2019.

INCLUDE WHEN CITING Published online January 3, 2020; DOI: 10.3171/2019.10.PEDS19377. 
with disability. The worldwide economic impact of the loss and decreased quality of life due to TBI is significant. The direct and indirect cost of TBI in the US alone is estimated to be $\$ 76.5$ billion (in 2010 US dollars). ${ }^{12}$

TBI occurs most often due to road traffic accidents (RTAs), specifically head injuries among pediatric and young populations riding motorcycles and bicycles. ${ }^{13,48}$ Head injuries are the leading cause of death in fatal motorcycle crashes. ${ }^{44}$ Of the approximately 14,000 deaths from road traffic injuries in Vietnam per year, $70 \%$ were related to motorcycles, of which $78 \%$ were attributed to head injuries. ${ }^{45}$ One estimate found that $40.2 \%$ of pediatric patients with head trauma in urban areas in the US were injured as bicyclists. ${ }^{19}$ Overall, RTAs are the most frequent cause of severe TBI and of TBI among younger populations worldwide. ${ }^{61}$ Helmet use can greatly decrease the morbidity and mortality from RTAs. A Cochrane review found that helmets reduced the risk of head, brain, and severe traumatic brain injury for all ages of bicyclists-by $63 \%-88 \% .^{72} \mathrm{~A}$ separate Cochrane review found that helmets reduced risk of death in motorcyclists by $42 \%$ and risk of head injury by $69 \% .4$

Despite evidence supporting helmet efficacy, their use is not standardized in most countries, and few countries have adopted and reinforced comprehensive laws. As of 2013 , the WHO estimates that only $24.61 \%$ of countries worldwide have motorcycle helmet laws that require drivers and passengers to wear helmets and require helmets to meet specific quality standards. ${ }^{77}$ In total, $38.77 \%$ have some form of helmet legislation requiring drivers and passengers to wear protective head gear. The lack of helmet legislation in LMICs is especially problematic, because motorcycles, scooters, and bicycles are often the most common method of wheeled transport. ${ }^{14}$ Motorcycles account for $95 \%$ of vehicles and are the primary mode of transportation for the majority of residents in Vietnam. ${ }^{42}$ In China, motorcycle ownership between 1987 and 2001 grew rapidly from $23 \%$ to $63 \%{ }^{80}$ In Pakistan, $61.2 \%$ of registered vehicles are 2- or 3-wheeled vehicles. ${ }^{63} \mathrm{In}$ Kenya, motorcycles make up more than $80 \%$ of all registered vehicles. ${ }^{3}$ Bicycles, scooters, and motorcycles are increasingly popular modes of transportation in LMICs, with young people and pediatric populations dependent on these modes of transportation to attend school, gain employment, and so on. Often passengers are unhelmeted, and pediatric and adolescent patients suffering TBI from RTAs are an increasing public health concern among younger populations (from infants to young adults) around the world. ${ }^{61}$

In light of globally low rates of helmet use and increasing incidence of TBI, a systematic review was conducted to answer the following question: "Are helmet laws correlated with decreased incidence of TBI from RTAs among younger populations worldwide?" Because TBI from RTAs tends to disproportionately affect pediatric and young adults, and is a leading cause for morbidity and mortality, ${ }^{60}$ this review focuses on the population $\leq$ 25 years of age. The aims of the study were as follows: 1) to identify existing evidence to support helmet advocacy and legislation; and 2) to provide a summary of the components of a successful helmet policy. The results of this
TABLE 1. Search terms

\begin{tabular}{cc}
\hline \multicolumn{1}{c}{ Database } & \multicolumn{1}{c}{ Search String } \\
\hline PubMed/ & $(((($ (“head injury") OR "brain injury”)) AND ((((legislation) \\
MEDLINE & OR law) OR program) OR policy)) AND helmet) AND \\
& (((child) OR pediatric) OR adolescent) \\
\hline SCOPUS & (TITLE-ABS-KEY (child OR pediatric OR adolescent) \\
& AND TITLE-ABS-KEY (helmet) AND TITLE-ABS- \\
& KEY (legislation OR law OR policy OR program) \\
& AND TITLE-ABS-KEY (“head injury” OR "brain \\
& injury")) \\
\hline
\end{tabular}

study potentiate pediatric neurosurgery advocacy efforts and serve as groundwork for TBI public health measures and advocacy globally. We emphasize the importance of primary prevention of unhelmeted TBI in a holistic approach to management methodologies.

\section{Methods}

A systematic review using PRISMA guidelines was conducted to investigate the efficacy of helmet laws globally. No review protocol exists for this topic. The National Library of Medicine PubMed and SCOPUS databases were searched for articles published or translated into English by using keywords associated with 4 areas as defined by the PICO (Population Intervention Comparison Outcome) framework. The search structure included patient population $\leq 25$ years of age, intervention of helmet law(s) in the context of improving transportation safety with helmets, and outcomes of bicycle- or motorcycle-related injuries or fatalities and helmet use. Databases were queried using the search terms detailed in Table 1.

After collection of search results, a citation search of key publications was performed to identify additional articles. Duplicate articles were removed and articles not available in English were excluded. All remaining articles were screened for full-text review based on the content of their title and abstract. Of articles deemed relevant for full-text review, the decision for final inclusion in analysis was determined based on criteria outlined in Table 2 . A second reviewer replicated the search strategy and disagreements were reconciled.

Complete inclusion and exclusion criteria are summarized in Table 2. Studies were also excluded if they failed to include a mandatory helmet use law in some form. The primary outcomes of interest were decreases in bicycle- or motorcycle-related injuries or fatalities. Secondary outcomes of interest were increase in helmet use or negative consequences such as decreases in bicycle or motorcycle use.

After selection of articles for inclusion in the review, bibliographic data, study aim, design and duration, study participants, intervention characteristics, and intervention effect data were extracted from each article. Studies were categorized into the following domains for handling of results: efficacy of bicycle helmet legislation, efficacy of motorcycle helmet legislation, comprehensive helmet laws, impact of socioeconomic status, and additional/miscellaneous findings. The quality of evidence was evaluated 
TABLE 2. Systematic review inclusion and exclusion criteria

\begin{tabular}{|c|c|c|}
\hline Characteristic & Inclusion Criteria & Exclusion Criteria \\
\hline Language & English or translated to English & Non-English \\
\hline Time period & From inception of databases to 2019 & NA \\
\hline Study design & $\begin{array}{l}\text { RCTs; non-RCTs; controlled before-\&-after studies; interrupted time series studies; } \\
\text { noncontrolled before-\&-after studies; cohort studies; cross-sectional studies } \\
\text { with comparators }\end{array}$ & $\begin{array}{l}\text { Opinion papers; noncomparative studies; qualita- } \\
\text { tive studies; traditional literature reviews; } \\
\text { theoretical papers }\end{array}$ \\
\hline Population & $\begin{array}{l}\text { Inclusion of newborn, infant, child, teenager, adolescent, or young adult popula- } \\
\text { tions ( } \leq 25 \text { years of age) }\end{array}$ & $\begin{array}{l}\text { Interventions including only population } \geq 26 \text { years } \\
\text { of age }\end{array}$ \\
\hline Intervention & Helmet legislation/law(s) & NA \\
\hline Comparator & No exposure; time bound; geographical controls & No comparator \\
\hline Context & Helmet use for methods of transportation made safer by helmets & $\begin{array}{l}\text { Nontransportation-related injuries (e.g., sports, } \\
\text { falls, etc.) }\end{array}$ \\
\hline \multirow[t]{2}{*}{ Outcomes } & Primary outcomes: decrease in incidence of TBI; improved outcomes for TBI & NA \\
\hline & Secondary outcomes: increase in helmet use; unintended negative consequences & NA \\
\hline
\end{tabular}

NA = not applicable.

based on study design grades extrapolated from Shadish et al. ${ }^{68}$ Grades are outlined in Table 3. Of note, grade E studies were not included in this review.

\section{Results}

From a total of 618 search results, 53 eligible studies were included in the review. Figure 1 shows the PRIMSA flowchart for article selection. No randomized controlled trials (RCTs) or non-RCTs were found. There was significant variation in study design and quality, with most studies using interrupted time series, controlled beforeand-after, noncontrolled before-and-after, cohort, or crosssectional study designs. Most studies examined one or more outcome (head injury, mortality, facial or neck injury, fatality) in relation to helmet use, in addition to helmet use itself. Forty-eight (90.6\%) studies were conducted in highincome countries (HICs). Of studies evaluating helmet legislation implemented in LMICs, all were restricted to the context of motorcycles. Included studies are detailed in Table 4. Forty-two (79.2\%) studies investigated universal mandatory restricted helmet laws for motorcycles or bicycles. Eleven studies investigated limited mandatory helmet laws with some age or region restrictions. Four studies investigated nonmandatory helmet interventions in addition to mandatory helmet laws. Studies were published from all continents except South America (Fig. 2).

\section{Evidence Supports the Effectiveness of Bicycle Helmet Legislation}

Among the 53 articles, 36 provided evidence of effectiveness in bicyclists. The evidence in this review supports the efficacy of mandatory use legislation in increasing helmet use and decreasing accident-related head injuries and fatalities among bicyclists $\leq 25$ years of age. ${ }^{34,37}$ Macpherson and Spinks found that bicycle helmet legislation implemented in HICs increases bicycle helmet use and reduces both bicycle-related mortality and head injuries. ${ }^{49}$ Two other meta-analyses of bicycle helmet laws in HICs found that legislation increases helmet use by varying magnitudes..$^{27,35}$ Overall, 19 of 20 articles measur-

TABLE 3. Evidence level and quality of study design

\begin{tabular}{|c|c|}
\hline Grade & Design \\
\hline AA & Systematic review or meta-analysis of RCTs \\
\hline \multirow[t]{2}{*}{ A } & Systematic review or meta-analysis of non-RCTs \\
\hline & RCT or cluster RCT \\
\hline \multirow[t]{5}{*}{ B } & Systematic review or meta-analysis of controlled studies without a pretest or uncontrolled study with a pretest \\
\hline & Non-RCT \\
\hline & Controlled before-\&-after study \\
\hline & Retrospective or prospective cohort study \\
\hline & Interrupted time series \\
\hline \multirow[t]{2}{*}{ C } & Systematic review or meta-analysis of cross-sectional studies \\
\hline & Noncontrolled before-\&-after study \\
\hline D & Cross-sectional study \\
\hline $\mathrm{E}$ & Case studies, case reports, traditional literature reviews, theoretical papers (excluded in this study) \\
\hline
\end{tabular}




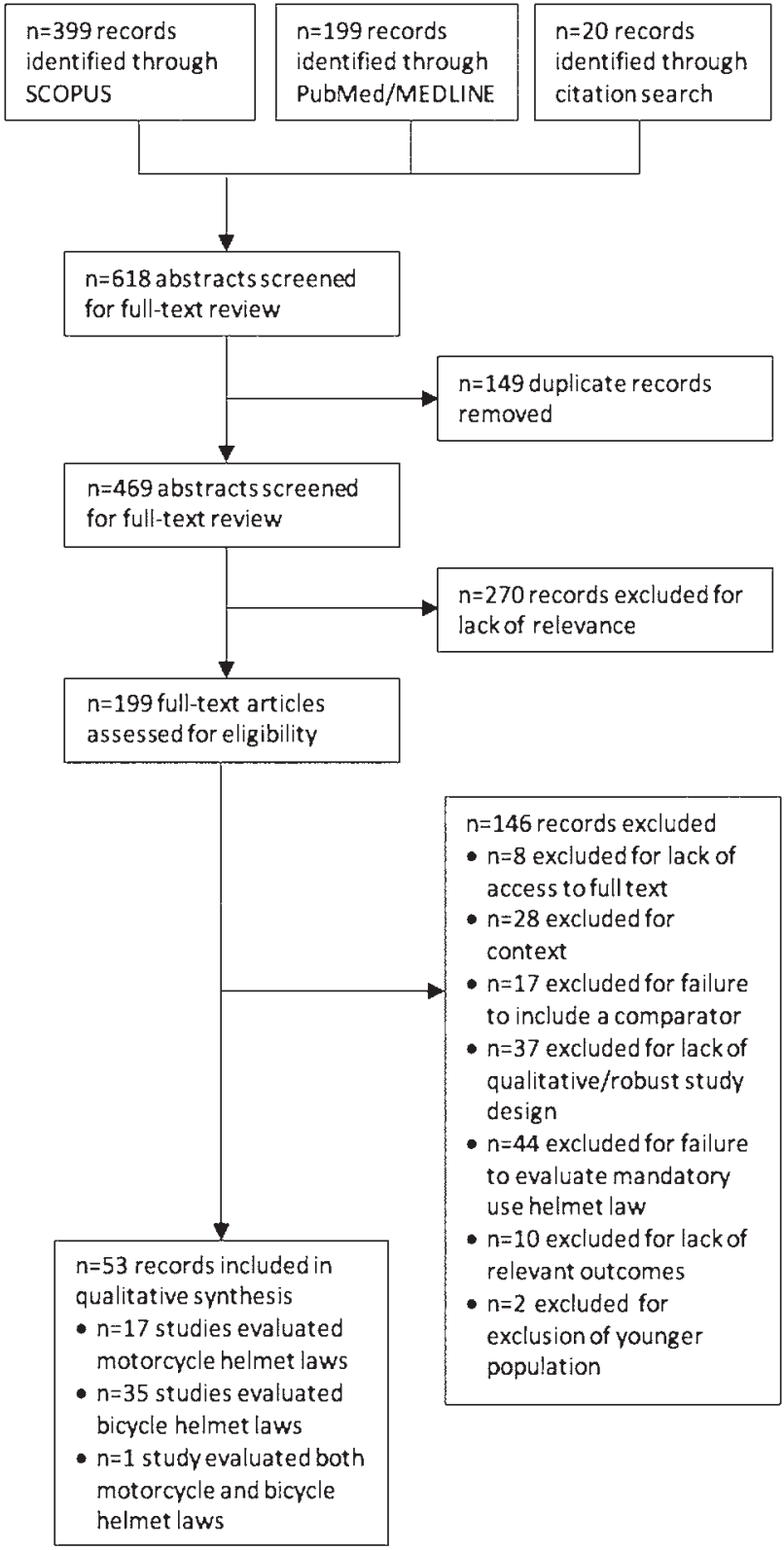

FIG. 1. PRISMA flowchart outlining the process of collecting and selecting abstracts and full-length articles.

ing helmet use supported the finding that bicycle-specific legislation increases helmet use among bicyclists. ${ }^{6,8-10,15,17}$, $22,25,27,29,32,33,35,50,53,65,68,70,77$ Ten of 13 articles measuring head injuries supported the finding that helmet legislation decreases bicycle-related head injuries. ${ }^{5,8,18,33,39,49,50,54,63,73} \mathrm{Six}$ of 7 articles measuring fatality supported the finding that helmet legislation decreases fatalities related to bicycling; mortality decreased by an estimated 15\%-30\% depending on the study. $9,23,39,50,51,75$

Castle et al. found no significant decrease in the percentage of patients with head injury; however, injury severity did decrease during the postlegislation period..$^{10}$ Two studies found no association between helmet legisla- tion and bicycle-related head injury: Williams et al. found that children living in areas with helmet legislation were more likely to wear helmets across all ages, but observed no difference in injury pattern with helmet legislation, ${ }^{78}$ and Leblanc et al. found higher helmet use postlegislation but no significant decrease in the proportion of head injuries among bicycle-related injuries. ${ }^{43}$ Of note, unlike Castle et al., Williams et al. and Leblanc et al. did not include severity of head injury as an outcome measure. .0,43,78 $^{-1,7}$ No studies were found investigating mandatory helmet use legislation for bicyclists in LMICs.

\section{Evidence Supports the Effectiveness of Motorcycle Helmet Legislation}

Among the 53 articles, 18 provided evidence in motorcyclists. Although less literature was found, the evidence in this review also supports the efficacy of helmet legislation in increasing helmet use, decreasing motorcyclerelated head injuries, and decreasing fatalities. No existing systematic reviews or meta-analyses were found that evaluated the efficacy of helmet legislation for motorcyclists. In an interrupted time series study of the repeal of a universal helmet law in Michigan, Saunders et al. found a 2-fold increase in the rate of unhelmeted motorcycle patients during the postrepeal period. ${ }^{64}$ Nine of 10 studies measuring head injuries supported the finding that helmet legislation reduces motorcycle-related head injuries. ${ }^{13,24}$, $26,30,33,56,63,66,72,80$ Six of 8 studies measuring fatalities supported the finding that helmet legislation reduces motorcycle-related fatalities. ${ }^{1,24,40,47,69,72}$ Of note, Saunders et al. and Ichikawa et al. found that motorcycle helmet laws decreased motorcycle-related head injuries but did not find an association with fatalities, ${ }^{30,64}$ whereas Tsai and Hemenway and $\mathrm{Ha}$ et al. found that motorcycle helmet laws were associated with decreases in both motorcycle-related head injuries and fatalities..$^{24,73}$ The only study not to find some positive association in measured outcomes of helmet legislation for motorcycles was Bachani et al., which found no statistical difference in the rate of helmet use among drivers or passengers in legislation and nonlegislation groups. ${ }^{2}$ The authors hypothesized that this was probably due to poor enforcement of the helmet policy.

In a noncontrolled before-and-after study, La Torre et al. published the only study to explicitly and exclusively include low-powered 2-wheeled vehicles (e.g., scooters or mopeds) in their analyses. ${ }^{41}$ They found that scooterrelated head trauma decreased after helmet legislation for scooters went into effect.

\section{Comprehensive Laws Are More Effective}

Ten studies compared the comprehensiveness of helmet legislation. Children and adolescents were found to benefit more from universal bicycle and motorcycle helmet laws than age-restricted helmet laws. ${ }^{27,55,74}$ For example, in the US, states with helmet laws restricted to motorcyclists $\leq$ 21 years of age had higher rates of motorcycle-related serious TBI among 18- to 20-year-olds than universal law states. ${ }^{74}$ Jewett et al. found that children were more likely to wear helmets if their caretakers wore helmets, underscoring the importance of inclusivity. ${ }^{32}$ Additionally, geo- 


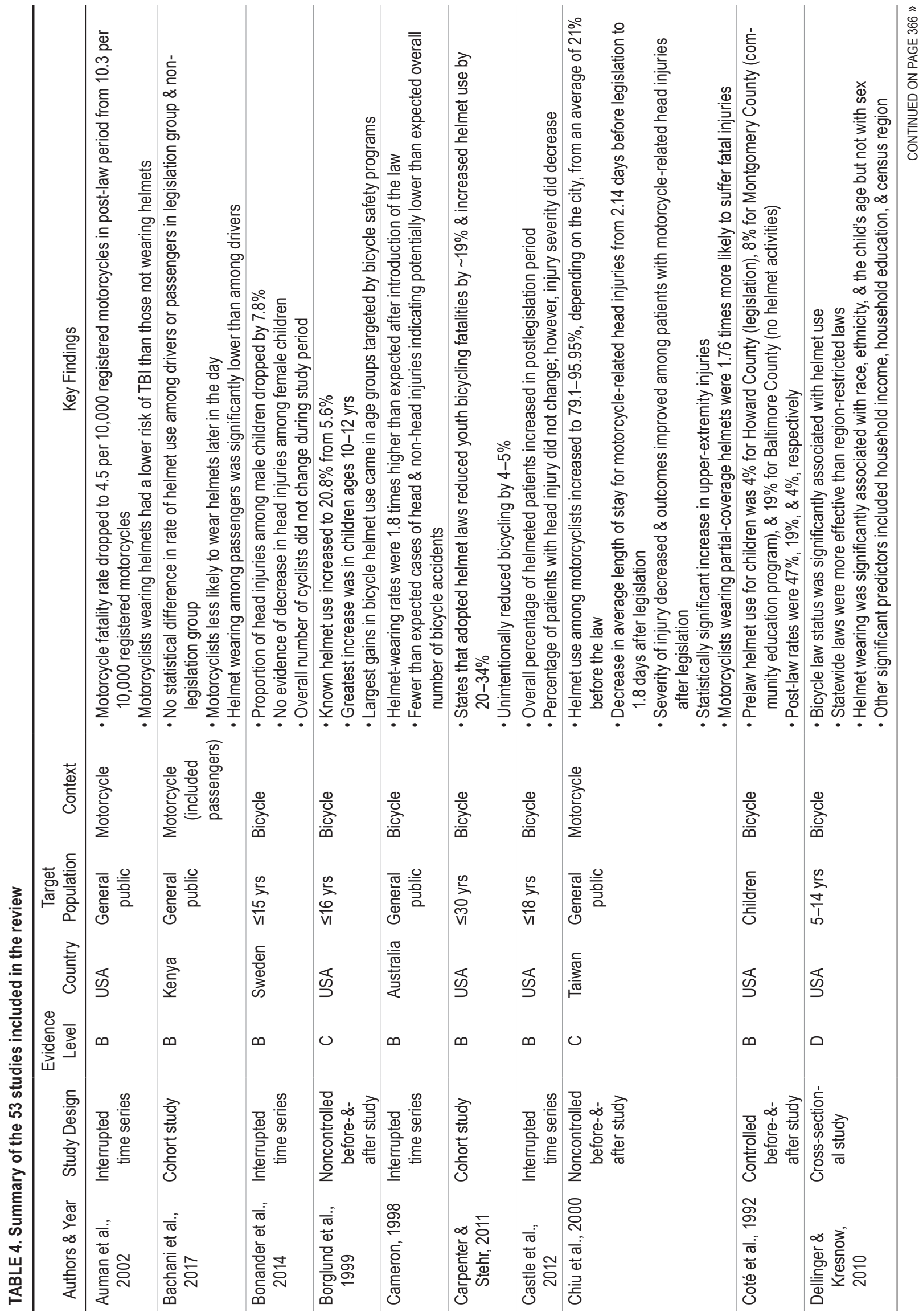




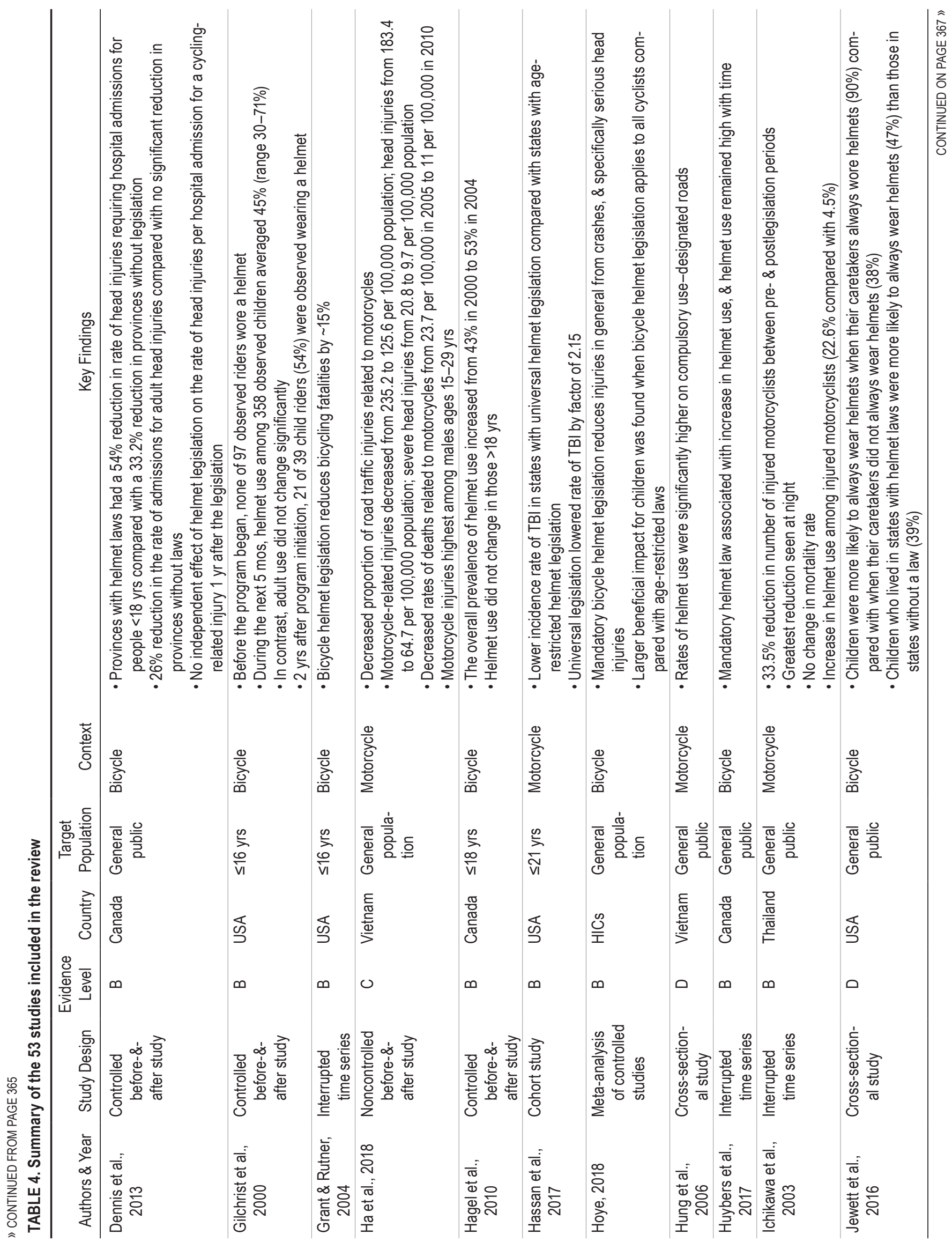


Du et al.

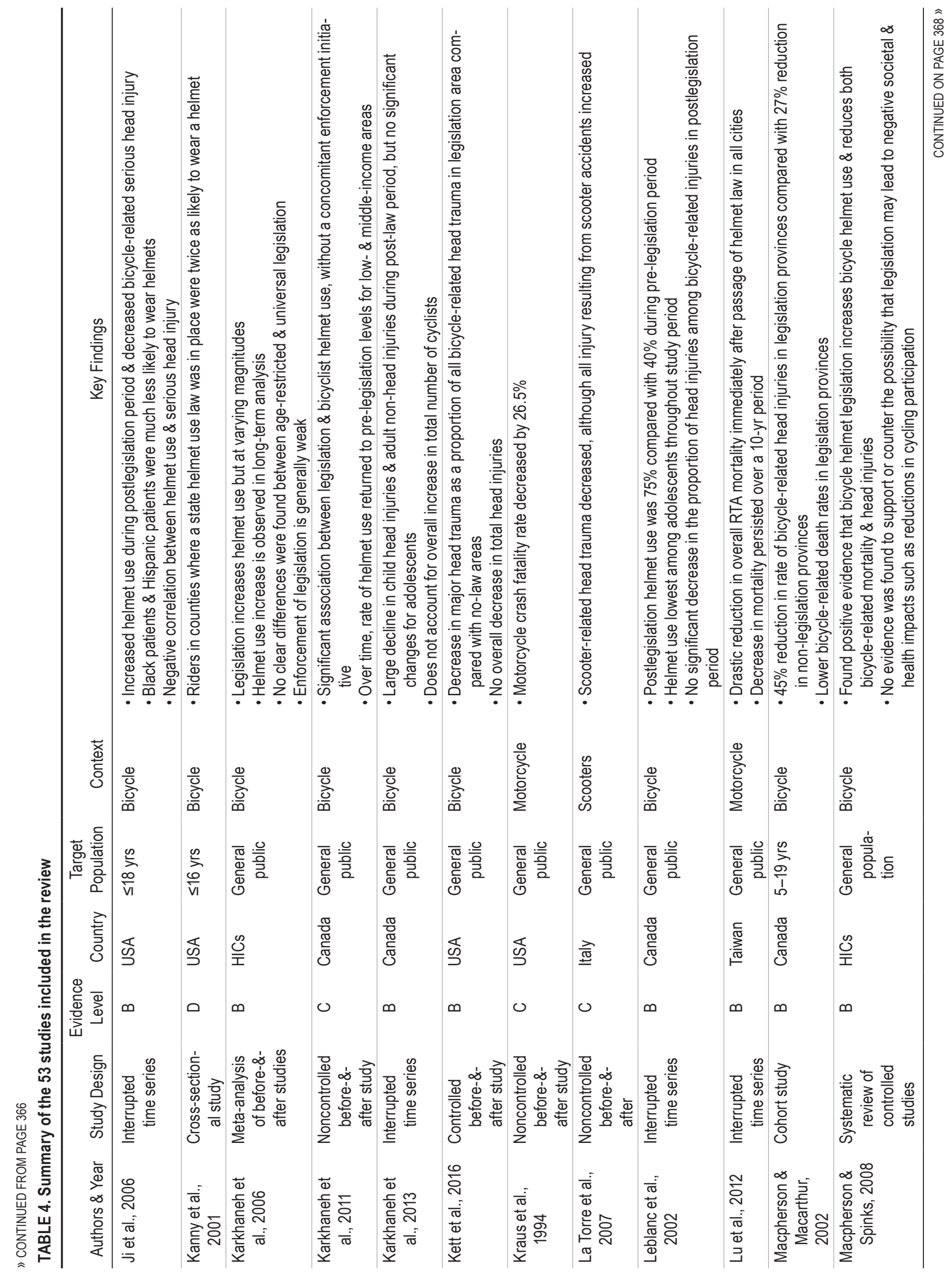




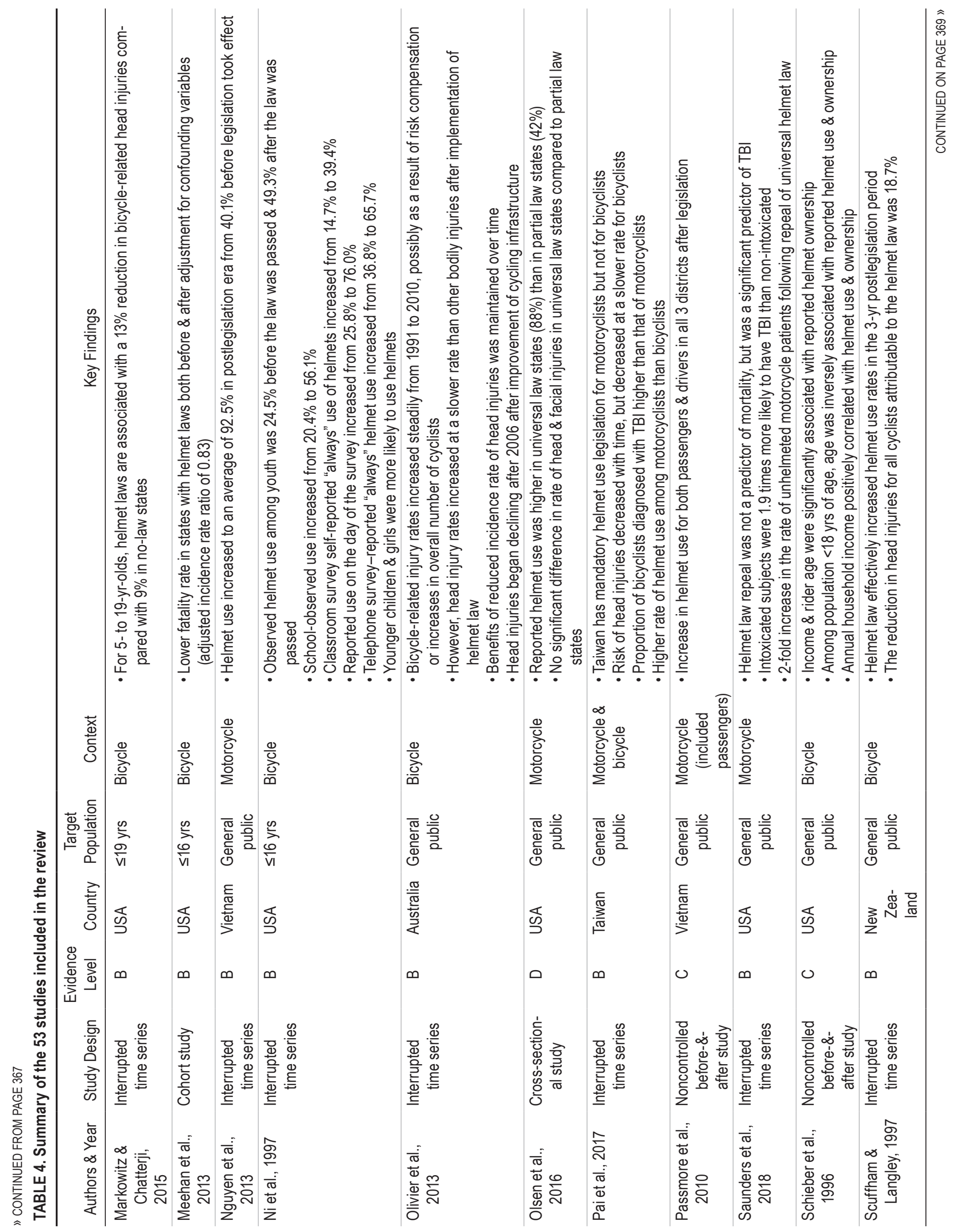


Du et al.

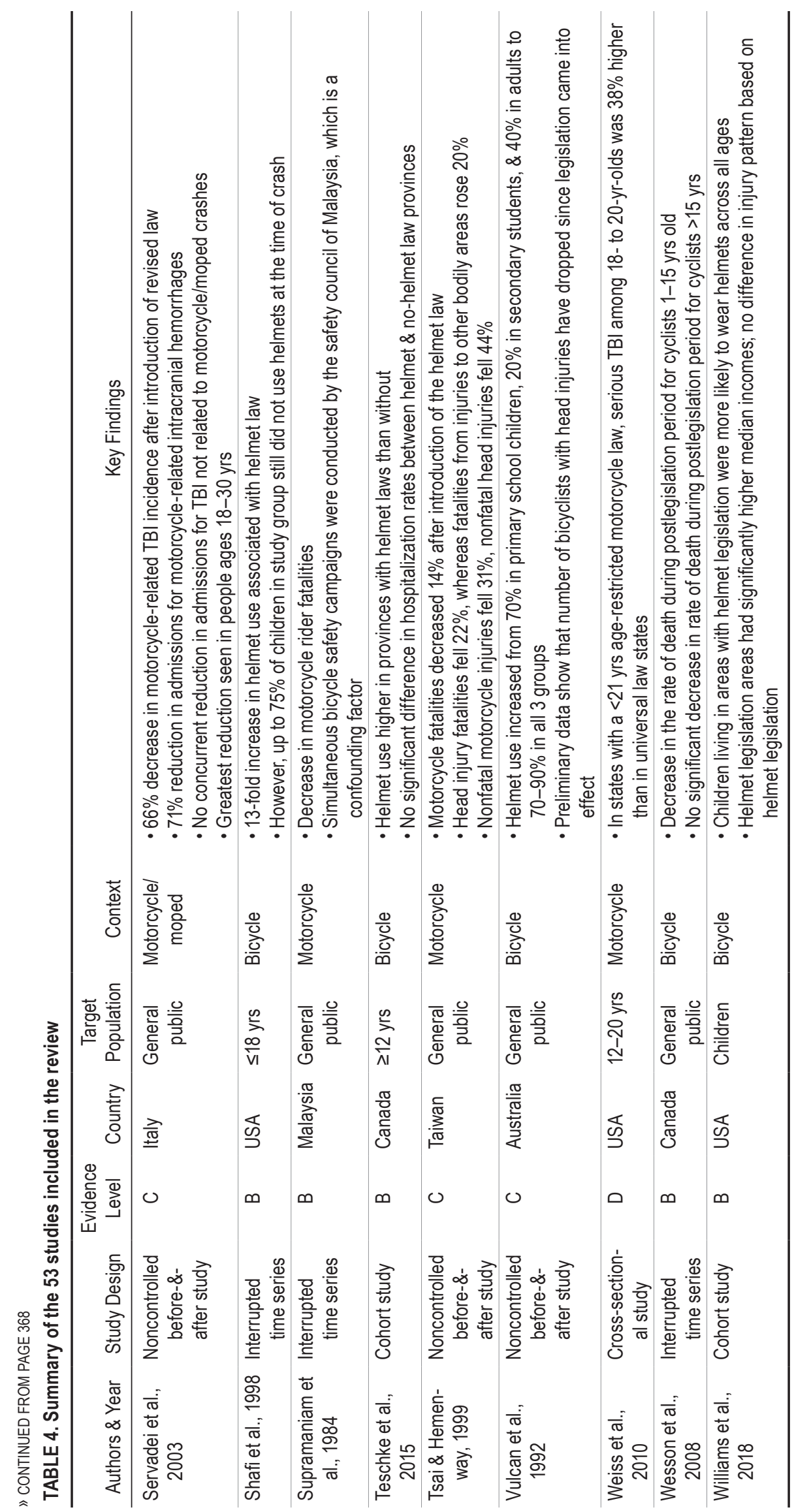




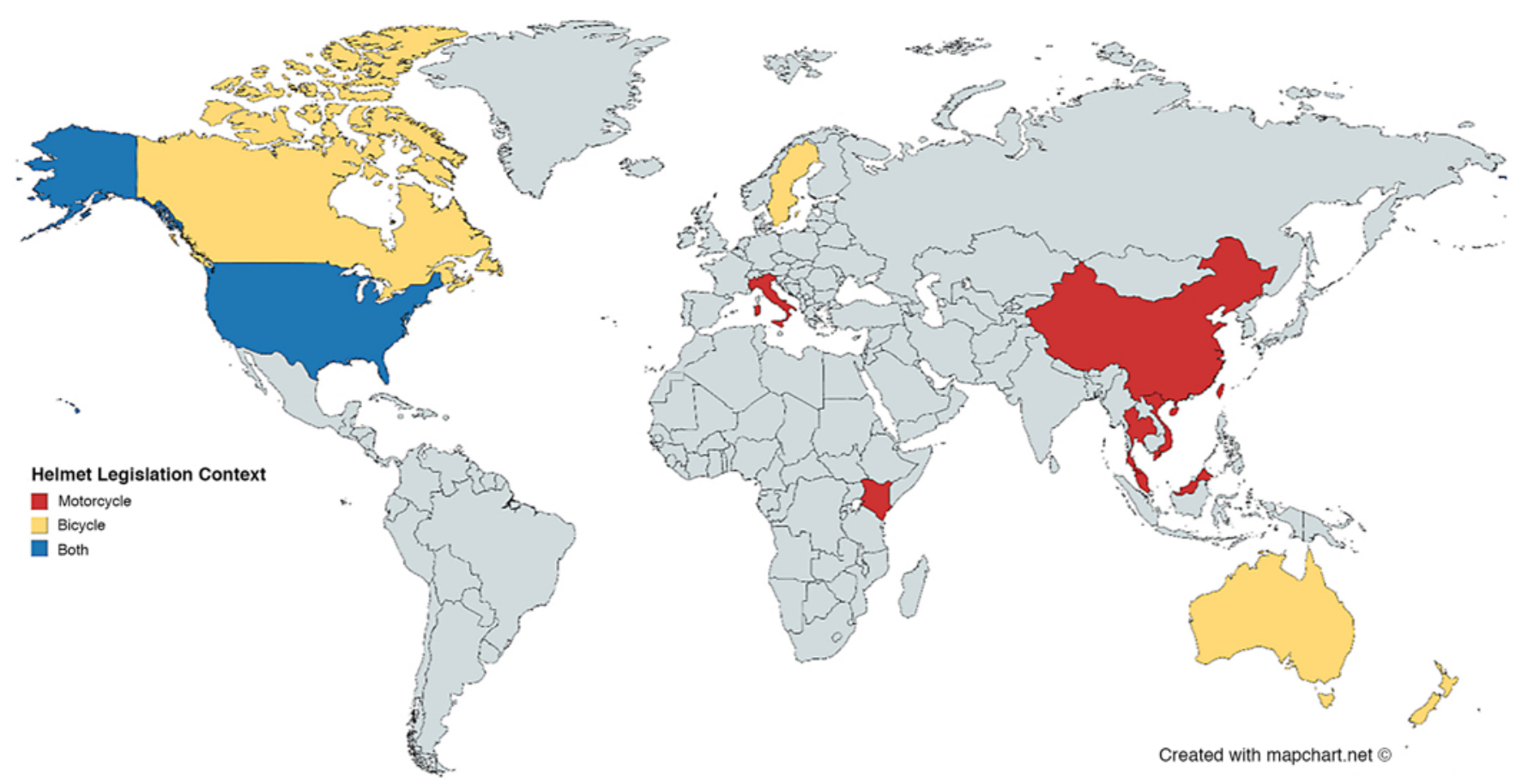

FIG. 2. Map illustrating global distribution of published studies for motorcycle and/or bicycle helmet legislation impact. Figure is available in color online only.

graphically encompassing laws have a greater impact than region-restricted legislation. ${ }^{17}$ Another example is helmet legislation in Vietnam, which initially only included a limited number of roads, ${ }^{52}$ Hung et al. found the law's failure to encompass all road types negatively impacted the legislation's efficacy, further highlighting the importance of broadly impacting laws. ${ }^{28}$

Although most studies examining helmet use patterns focused on the primary cyclist or driver, another consideration for a broader impact is the passenger. Bachani et al. found that helmet wearing among passengers on motorcycles in Kenya was significantly lower than for drivers. ${ }^{2}$ Passmore et al. found that motorcycle laws in Vietnam successfully increased helmet use for passengers in addition to drivers.$^{60}$ By including riders and their passengers, laws can protect a larger number of people.

The last consideration for comprehensive legislation is whether or not the law standardizes the quality of the helmet as well as helmet type. Chiu et al. found that the number of motorcycle fatalities was influenced by high rates of poor-quality helmets; partial-coverage helmets were associated with a 1.76 times increased likelihood of fatal injury. ${ }^{13}$ By accounting for the quality of helmet protection, a higher level of safety can be promoted.

\section{Impact of Socioeconomic Status}

One important barrier to access and a special consideration, especially in low-income communities and countries, is the impact of socioeconomic status. Despite initial increases in helmet use among children of all socioeconomic levels after implementation of a bicycle helmet law in Canada, Karkhaneh et al. found that over time, the rate of helmet use returned to prelegislation levels for low- and middle-income areas. ${ }^{36}$ Dellinger and Kresnow also found that household income and household education were significant predictors for the impact of bicycle helmet laws on children ages 5 to 14 years old in the US..$^{17}$ Additionally, in LMICs, bicycle helmet use and ownership was positively related to annual household income. ${ }^{64}$ These findings underscore the importance of access to safety equipment when considering the implementation of helmet safety laws.

\section{Additional Advocacy Considerations}

The studies included in this review support helmet legislation as one of the most effective primary interventions to prevent TBI from RTAs; however, educational and safety initiatives should not be discounted. A study comparing bicycle helmet mandatory use legislation to an educational program in Maryland found that areas with mandatory use legislation had a greater increase in helmet use among children. ${ }^{15}$ However, Borglund et al. found that the largest increase in bicycle helmet use among those $\leq 16$ years old occurred after helmet legislation was applied to groups targeted by bicycle safety programs. ${ }^{6} \mathrm{~A}$ final consideration is unintended consequences. Although legislation is often a supportive measure to ensure compliance with safety protocols, there can be unintentional negative impacts of restrictive laws. Carpenter and Stehr found that bicycle helmet legislation in the US was associated with a $4 \%-5 \%$ reduction in bicycling. ${ }^{9}$

\section{Discussion}

This systematic review underscores the importance of 
safety legislation in aiming to reduce TBI globally. The overwhelming majority of studies identified in this review support the use of helmet laws to decrease the incidence of TBI from RTAs among younger populations worldwide. Helmet legislation is associated with increased helmet use among bicyclists and decreased RTA-related head injuries and fatalities among motorcyclists and bicyclists.

One consideration highlighted from this review is the differing impact of helmet legislation in HICs versus LMICs. Whereas principles such as education and helmet use for primary riders may be widely applicable, special considerations for LMICs must be taken into account, including road type, infrastructure, road traffic, helmet quality/availability, and law enforcement. Bachani et al. found that mandating helmet use for all motorcyclists, drivers, and passengers was not associated with significant increases in helmet use, and that knowledge of the benefits of helmet use was high but did not translate into actual use, perhaps due to low police enforcement of the motorcycle helmet legislation. ${ }^{3}$ Following initial introduction of helmet laws for motorcycles in Vietnam, poor compliance to helmet laws also was attributed to low penalties and limited enforcement. ${ }^{28}$ Since their first iteration, however, several amendments to Vietnam's helmet laws were passed between 2005 and 2008, and helmet use has improved greatly as a result. The amendments made laws applicable to all road types, increased fines for not wearing a helmet, and strengthened provisions for quality assurance inspection of helmets to ensure they meet national standards. ${ }^{28,59}$ By broadening the reach of the law and including more considerations specific to their country, as well as more impactful penalties, enforcement of the law as well as outcomes were improved. After implementation of these comprehensive laws in Vietnam, Passmore et al. found that helmet use among both passengers and drivers exceeded $80 \%$ in all districts - a vast improvement from prelegislation compliance, which ranged between $25 \%$ and $65 \%$ for drivers and between $20 \%$ and $45 \%$ for passengers in the same provinces. ${ }^{60}$

This review also brings up the concept of how best to implement and enforce helmet legislation. There is a need for adequate enforcement infrastructure in addition to the law itself., ${ }^{2,328,59}$ Not only is legislative infrastructure required, but organized groups to implement and effect change also are required for legislative success. Enforcement of helmet laws depends on sound legislation, invested organizational bodies to implement change locally, buy-in from the community and local stakeholders, access to affordable helmets, and a perceived need to effect change. Therefore, when setting enforcement policies, such as a threshold for fines or penalties, policy makers should balance the magnitude with potential unintended consequences. Penalties should aim to incentivize behavioral changes without being too restrictive, negatively impacting the ability of families to provide basic necessities such as education, food, power, and so on. After enforcement policies are implemented, governments also must carry out programs to audit compliance. This could include monitoring the rate of helmet noncompliance citations issued, monitoring the rate of helmet use among those injured in RTAs involving bicycles or motorcycles, or stationing auditors at commonly used roads to collect data on helmet use rates.

Directly related to helmet legislation are barriers that impede compliance with helmet laws, including access to and financial barriers to acquiring helmets, health literacy regarding helmet use, and individual socioeconomic status. Schieber et al. found that lower socioeconomic status is correlated with reduced helmet compliance..$^{65}$ Similarly, Parkin et al. found that an educational strategy to increase helmet use was only effective for children living in highincome areas. ${ }^{58}$ These authors later went on to study a helmet subsidy program to explore whether help with financial costs of a helmet could mediate decreased helmet use among families at lower socioeconomic levels, but found that this had no effect on helmet use in children living in low-income areas. ${ }^{57} \mathrm{~A}$ cross-sectional survey of 1061 children living in low-income areas of Nottingham, UK, found that children in underprivileged areas were less likely to own a helmet, but were not less likely to wear the helmet if they owned one. ${ }^{38}$ In helmet legislation implementation, barriers to helmet access and affordability are a significant challenge. Programs such as helmet subsidy or rebate initiatives are a possible solution when applied with community-based partners and target population input.

Another obstacle to helmet adherence is the quality of the helmets that are readily accessible. One of the most frequent reasons that younger people report for not wearing helmets is discomfort or ill-fitting equipment. ${ }^{3,11,14,20 \text {, }}$ 46,62 Improved helmet comfort and fit may improve safety and compliance with helmet laws. In LMICs, the quality of helmets may not be regulated, posing another concern. Zamani-Alavijeh et al. estimated that approximately $23 \%$ of Iranian motorcyclists use nonstandard or partial helmets that cover only part of the head. ${ }^{79}$ These helmets do not function properly and therefore do not effectively protect against head trauma morbidity or mortality..$^{13}$ It is thought that failure to standardize helmets may limit the full impact of motorcycle helmet laws due to the widespread availability of cheap, nonstandard helmets. ${ }^{16}$

Regarding cultural acceptance of helmet use, establishing helmets as a social norm is important. Several studies have found that younger populations are more likely to wear helmets if the people who surround them also wear helmets, which may explain the apparent benefit of universal helmet laws. ${ }^{4,20,21,38}$ In general, improved helmet use among all populations can augment helmet use in young and pediatric populations. Another consideration to improve cultural acceptance of helmet laws is to apply a more tailored approach, incorporating considerations for transportation modes specific to locale, for example, scooters in Italy and boda bodas in Uganda. ${ }^{16,41}$ Failure to incorporate and enforce legislation for primary riders and passengers in such a context may limit the full benefits of helmets to reduce head injuries.

Although helmet legislation is more effective than nonmandatory helmet programs, such as education programs or public safety campaigns, nonmandatory initiatives still have value and should be implemented concurrently with compulsory use legislation. Four studies included in the review explicitly considered the impact of nonmandatory helmet programs in addition to mandatory helmet pro- 
TABLE 5. Components of a successful helmet legislation to prevent TBI incurred during RTAs

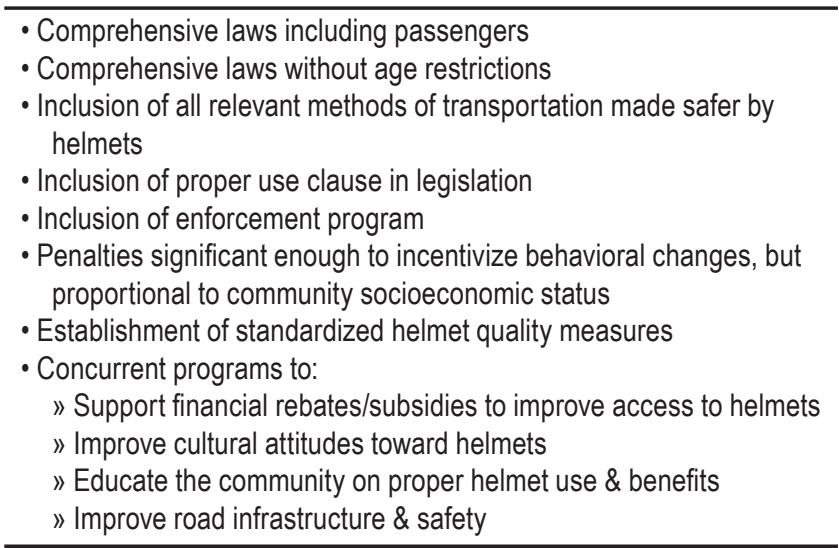

grams. Years before its first introduction of helmet legislation for bicyclists, Canada implemented myriad schoolbased programs and bicycle safety initiatives; it is thought that these programs acted as primers for community acceptance of helmet laws, changing cultural perceptions and augmenting compliance. ${ }^{43}$ Last, an important aspect of bicycle and motorcycle safety that must be considered is the infrastructure of roads. Olivier et al. found that the improvement of road infrastructure amplified the decline in TBI after implementation of a bicycle helmet law in Australia. ${ }^{55}$ Infrastructure projects are often large undertakings and expensive, requiring governmental finance and coordination; however, we believe a safer road is one of the key steps to a safe ride and a decrease in TBI for cyclists and riders.

Based on our findings, we propose several key considerations for the successful policy making and enforcement of compulsory use helmet laws to decrease TBI from RTAs; these considerations are displayed in Table 5. These considerations are for all caretakers of patients with TBI from RTAs, including but not limited to neurosurgeons. Laws should be comprehensive and include both primary riders and passengers, all age groups, all modes of transportation made safer by helmets, a proper use clause, and standardized helmet quality measures. Legislation enforcement methods also should be considered to improve compliance and outcomes. While policy change and enforcement are instrumental in safety and the prevention of TBI, community-specific factors must be considered when effecting change in different environments. No single approach will work for all communities, and special consideration must also be given to individual socioeconomic, cultural, and infrastructural barriers to helmet use. Additionally, these recommendations should be viewed with consideration of the poor quality of evidence. No RCTs or non-RCTs were found to support these findings. Further limitations are outlined in the following section.

\section{Limitations of the Study}

This systematic review has several limitations. Only published studies were included, putting results at risk for publication bias, in that our results overestimate the number of positive and significant study results. Studies without intervention impact are less likely to be published and are generally underrepresented in the literature. The quality of evidence also was relatively poor and included no RCTs. The lack of RCTs means that all results are subject to selection bias. Overall, there is a need for more investigation into the impact of mandatory helmet use laws globally, especially in LMICs. Only 1 study systematically and explicitly observed for negative outcomes as a result of the helmet legislation. Although the results of this systematic review indicate that the impact of helmet legislation is generally positive, this review may overlook unintended or negative consequences, such as direct and indirect costs of helmet advocacy and legislation. Unfavorable outcomes include decreased use of more environmentally efficient transportation methods in favor of methods that do not require helmet use. Mandatory helmet legislation also may be viewed as an overbearing or authoritarian government action impeding individual freedoms. Also, articles were limited to the English language; therefore, studies not written in English or not yet translated were not included, and this may have excluded interventions that were well received and applied in non-English-speaking communities. Additionally, because our review excluded qualitative studies, some of the subtler nuances regarding cultural acceptance and barriers to helmet implementation and use in specific communities may not have been identified as part of this study. Last, no meta-analysis was conducted as part of this systematic review, allowing us to make assumptions from our findings but not to draw statistically significant conclusions.

\section{Conclusions}

We present a thorough review of the impact of legislative advocacy regarding helmet use in pediatric TBI. We identify key aspects of legislative objectives that aim to improve helmet use and safety. By better understanding the role of legislation in primary prevention of head injury, we believe that neurosurgeons can act as better advocates for their patients and communities in understanding the impact and prevention of pediatric unhelmeted TBI.

\section{References}

1. Auman KM, Kufera JA, Ballesteros MF, Smialek JE, Dischinger PC: Autopsy study of motorcyclist fatalities: the effect of the 1992 Maryland motorcycle helmet use law. Am J Public Health 92:1352-1355, 2002

2. Bachani AM, Branching C, Ear C, Roehler DR, Parker EM, Tum S, et al: Trends in prevalence, knowledge, attitudes, and practices of helmet use in Cambodia: results from a two year study. Injury 44 (Suppl 4):S31-S37, 2013

3. Bachani AM, Hung YW, Mogere S, Akunga D, Nyamari J, Hyder AA: Helmet wearing in Kenya: prevalence, knowledge, attitude, practice and implications. Public Health 144S:S23-S31, 2017

4. Bianco A, Trani F, Santoro G, Angelillo IF: Adolescents' attitudes and behaviour towards motorcycle helmet use in Italy. Eur J Pediatr 164:207-211, 2005

5. Bonander C, Nilson F, Andersson R: The effect of the Swedish bicycle helmet law for children: an interrupted time series study. J Safety Res 51:15-22, 2014

6. Borglund ST, Hayes JS, Eckes JM: Florida's bicycle helmet 
law and a bicycle safety educational program: did they help? J Emerg Nurs 25:496-500, 1999

7. Bruns J Jr, Hauser WA: The epidemiology of traumatic brain injury: a review. Epilepsia 44 (s10):2-10, 2003

8. Cameron T: Self-insured health care plans: are they fair to employees with HIV/AIDS? J Health Soc Policy 10:23-40, 1998

9. Carpenter CS, Stehr M: Intended and unintended consequences of youth bicycle helmet laws. J Law Econ 54:305324, 2011

10. Castle SL, Burke RV, Arbogast H, Upperman JS: Bicycle helmet legislation and injury patterns in trauma patients under age 18. J Surg Res 173:327-331, 2012

11. Centers for Disease Control and Prevention: Mandatory bicycle helmet use-Victoria, Australia. MMWR Morb Mortal Wkly Rep 42:359-363, 1993

12. Centers for Disease Control and Prevention: Traumatic brain injury \& concussion: severe TBI. (https://www.cdc.gov/ traumaticbraininjury/severe.html) [Accessed October 25, 2019]

13. Chiu WT, Kuo CY, Hung CC, Chen M: The effect of the Taiwan motorcycle helmet use law on head injuries. Am J Public Health 90:793-796, 2000

14. Conrad P, Bradshaw YS, Lamsudin R, Kasniyah N, Costello C: Helmets, injuries and cultural definitions: motorcycle injury in urban Indonesia. Accid Anal Prev 28:193-200, 1996

15. Coté TR, Sacks JJ, Lambert-Huber DA, Dannenberg AL, Kresnow MJ, Lipsitz CM, et al: Bicycle helmet use among Maryland children: effect of legislation and education. Pediatrics 89:1216-1220, 1992

16. Craft G, Van Bui T, Sidik M, Moore D, Ederer DJ, Parker EM, et al: A comprehensive approach to motorcycle-related head injury prevention: experiences from the field in Vietnam, Cambodia, and Uganda. Int J Environ Res Public Health 14:14, 2017

17. Dellinger AM, Kresnow MJ: Bicycle helmet use among children in the United States: the effects of legislation, personal and household factors. J Safety Res 41:375-380, 2010

18. Dennis J, Ramsay T, Turgeon AF, Zarychanski R: Helmet legislation and admissions to hospital for cycling related head injuries in Canadian provinces and territories: interrupted time series analysis. BMJ 346: $\{2674,2013$

19. Durkin MS, Laraque D, Lubman I, Barlow B: Epidemiology and prevention of traffic injuries to urban children and adolescents. Pediatrics 103:e74, 1999

20. Finch CF: Teenagers' attitudes towards bicycle helmets three years after the introduction of mandatory wearing. Inj Prev 2:126-130, 1996

21. Fuentes C, Eugnia Gras M, Font-Mayolas S, Bertran C, Sullman MJM, Ballester D: Expectations of efficacy, social influence and age as predictors of helmet-use in a sample of Spanish adolescents. Transp Res Part F Traffic Psychol Behav 13:289-296, 2010

22. Gilchrist J, Schieber RA, Leadbetter S, Davidson SC: Police enforcement as part of a comprehensive bicycle helmet program. Pediatrics 106:6-9, 2000

23. Grant D, Rutner SM: The effect of bicycle helmet legislation on bicycling fatalities. J Policy Anal Manage 23:595-611, 2004

24. Ha NT, Ederer D, Vo VAH, Pham AV, Mounts A, Nolen LD, et al: Changes in motorcycle-related injuries and deaths after mandatory motorcycle helmet law in a district of Vietnam. Traffic Inj Prev 19:75-80, 2018

25. Hagel BE, Lee RS, Karkhaneh M, Voaklander D, Rowe BH: Factors associated with incorrect bicycle helmet use. Inj Prev 16:178-184, 2010

26. Hassan A, Jokar TO, Rhee P, Ibraheem K, Kulvatunyou N, Anderson KT, et al: More helmets fewer deaths: motorcycle helmet legislation impacts traumatic brain injury-related mortality in young adults. Am Surg 83:541-546, 2017
27. Hoye A: Recommend or mandate? A systematic review and meta-analysis of the effects of mandatory bicycle helmet legislation. Accid Anal Prev 120:239-249, 2018

28. Hung DV, Stevenson MR, Ivers RQ: Prevalence of helmet use among motorcycle riders in Vietnam. Inj Prev 12:409-413, 2006

29. Huybers S, Fenerty L, Kureshi N, Thibault-Halman G, LeBlanc JC, Clarke DB, et al: Long-term effects of education and legislation enforcement on all-age bicycle helmet use: a longitudinal study. J Community Health 42:83-89, 2017

30. Ichikawa M, Chadbunchachai W, Marui E: Effect of the helmet act for motorcyclists in Thailand. Accid Anal Prev 35:183-189, 2003

31. James SL, Theadom A, Ellenbogen RG, Bannick MS, Montjoy-Venning W, Lucchesi LR, et al: Global, regional, and national burden of traumatic brain injury and spinal cord injury, 1990-2016: a systematic analysis for the Global Burden of Disease Study 2016. Lancet Neurol 18:56-87, 2019

32. Jewett A, Beck LF, Taylor C, Baldwin G: Bicycle helmet use among persons 5 years and older in the United States, 2012. J Safety Res 59:1-7, 2016

33. Ji M, Gilchick RA, Bender SJ: Trends in helmet use and head injuries in San Diego County: the effect of bicycle helmet legislation. Accid Anal Prev 38:128-134, 2006

34. Kanny D, Schieber RA, Pryor V, Kresnow MJ: Effectiveness of a state law mandating use of bicycle helmets among children: an observational evaluation. Am J Epidemiol 154:1072-1076, 2001

35. Karkhaneh M, Kalenga JC, Hagel BE, Rowe BH: Effectiveness of bicycle helmet legislation to increase helmet use: a systematic review. Inj Prev 12:76-82, 2006

36. Karkhaneh M, Rowe BH, Saunders LD, Voaklander DC, Hagel BE: Bicycle helmet use four years after the introduction of helmet legislation in Alberta, Canada. Accid Anal Prev 43:788-796, 2011

37. Karkhaneh M, Rowe BH, Saunders LD, Voaklander DC, Hagel BE: Trends in head injuries associated with mandatory bicycle helmet legislation targeting children and adolescents. Accid Anal Prev 59:206-212, 2013

38. Kendrick D, Royal S: Inequalities in cycle helmet use: cross sectional survey in schools in deprived areas of Nottingham. Arch Dis Child 88:876-880, 2003

39. Kett P, Rivara F, Gomez A, Kirk AP, Yantsides C: The effect of an all-ages bicycle helmet law on bicycle-related trauma. J Community Health 41:1160-1166, 2016

40. Kraus JF, Peek C, McArthur DL, Williams A: The effect of the 1992 California motorcycle helmet use law on motorcycle crash fatalities and injuries. JAMA 272:1506-1511, 1994

41. La Torre G, Van Beeck E, Bertazzoni G, Ricciardi W: Head injury resulting from scooter accidents in Rome: differences before and after implementing a universal helmet law. Eur J Public Health 17:607-611, 2007

42. Le LC, Blum RW: Road traffic injury among young people in Vietnam: evidence from two rounds of national adolescent health surveys, 2004-2009. Glob Health Action 6:1-9, 2013

43. Leblanc JC, Beattie TL, Culligan C: Effect of legislation on the use of bicycle helmets. CMAJ 166:592-595, 2002

44. Lin MR, Kraus JF: A review of risk factors and patterns of motorcycle injuries. Accid Anal Prev 41:710-722, 2009

45. Liu BC, Ivers R, Norton R, Boufous S, Blows S, Lo SK: Helmets for preventing injury in motorcycle riders. Cochrane Database Syst Rev (1):CD004333, 2008

46. Loubeau PR: Exploration of the barriers to bicycle helmet use among 12 and 13 year old children. Accid Anal Prev 32:111-115, 2000

47. Lu TH, Lai CH, Chiang TL: Reducing regional inequality in mortality from road traffic injuries through enforcement of the mandatory motorcycle helmet law in Taiwan. Inj Prev 18:150-157, 2012 
48. Maas AI, Stocchetti N, Bullock R: Moderate and severe traumatic brain injury in adults. Lancet Neurol 7:728-741, 2008

49. Macpherson A, Spinks A: Bicycle helmet legislation for the uptake of helmet use and prevention of head injuries. Cochrane Database Syst Rev (3):CD005401, 2008

50. Macpherson AK, Macarthur C: Bicycle helmet legislation: evidence for effectiveness. Pediatr Res 52:472, 2002

51. Markowitz S, Chatterji P: Effects of bicycle helmet laws on children's injuries. Health Econ 24:26-40, 2015

52. Meehan WP III, Lee LK, Fischer CM, Mannix RC: Bicycle helmet laws are associated with a lower fatality rate from bicycle-motor vehicle collisions. J Pediatr 163:726-729, 2013

53. Nguyen HT, Passmore J, Cuong PV, Nguyen NP: Measuring compliance with Viet Nam's mandatory motorcycle helmet legislation. Int J Inj Contr Saf Promot 20:192-196, 2013

54. Ni H, Sacks JJ, Curtis L, Cieslak PR, Hedberg K: Evaluation of a statewide bicycle helmet law via multiple measures of helmet use. Arch Pediatr Adolesc Med 151:59-65, 1997

55. Olivier J, Walter SR, Grzebieta RH: Long term bicycle related head injury trends for New South Wales, Australia following mandatory helmet legislation. Accid Anal Prev 50:1128-1134, 2013

56. Olsen CS, Thomas AM, Singleton M, Gaichas AM, Smith TJ, Smith GA, et al: Motorcycle helmet effectiveness in reducing head, face and brain injuries by state and helmet law. Inj Epidemiol 3:8, 2016

57. Pai CW, Chen YC, Lin HY, Chen PL: A population-based case-control study of hospitalisation due to head injuries among bicyclists and motorcyclists in Taiwan. BMJ Open 7:e018574, 2017

58. Parkin PC, Hu X, Spence LJ, Kranz KE, Shortt LG, Wesson DE: Evaluation of a subsidy program to increase bicycle helmet use by children of low-income families. Pediatrics 96:283-287, 1995

59. Parkin PC, Spence LJ, Hu X, Kranz KE, Shortt LG, Wesson DE: Evaluation of a promotional strategy to increase bicycle helmet use by children. Pediatrics 91:772-777, 1993

60. Passmore JW, Nguyen LH, Nguyen NP, Olivé JM: The formulation and implementation of a national helmet law: a case study from Viet Nam. Bull World Health Organ 88:783787, 2010

61. Peeters W, van den Brande R, Polinder S, Brazinova A, Steyerberg EW, Lingsma HF, et al: Epidemiology of traumatic brain injury in Europe. Acta Neurochir (Wien) 157:16831696,2015

62. Roozenbeek B, Maas AIR, Menon DK: Changing patterns in the epidemiology of traumatic brain injury. Nat Rev Neurol 9:231-236, 2013

63. Saeed M, Siddiqui SM, Khan UR, Swaroop M: Perceptions regarding helmet use: a cross-sectional survey of female pillions in Karachi, Pakistan. J Surg Res 211:261-265, 2017

64. Saunders RN, Adams NS, Chapman AJ, Davis AT, Koehler TJ, Durling LT, et al: The impact of the repeal of Michigan's universal helmet law on traumatic brain injury: a statewide analysis. Am J Surg 215:424-427, 2018

65. Schieber RA, Kresnow MJ, Sacks JJ, Pledger EE, O’Neil JM, Toomey KE: Effect of a state law on reported bicycle helmet ownership and use. Arch Pediatr Adolesc Med 150:707712,1996

66. Scuffham PA, Langley JD: Trends in cycle injury in New Zealand under voluntary helmet use. Accid Anal Prev 29:19, 1997

67. Servadei F, Begliomini C, Gardini E, Giustini M, Taggi F, Kraus J: Effect of Italy's motorcycle helmet law on traumatic brain injuries. Inj Prev 9:257-260, 2003

68. Shadish WR, Cook TD, Campbell DT: Experimental and Quasi-Experimental Designs for Generalized Causal Inference. Boston: Houghton Mifflin Company, 2002
69. Shafi S, Gilbert JC, Loghmanee F, Allen JE, Caty MG, Glick PL, et al: Impact of bicycle helmet safety legislation on children admitted to a regional pediatric trauma center. J Pediatr Surg 33:317-321, 1998

70. Supramaniam V, van Belle G, Sung JFC: Fatal motorcycle accidents and helmet laws in Peninsular Malaysia. Accid Anal Prev 16:157-162, 1984

71. Teschke K, Koehoorn M, Shen H, Dennis J: Bicycling injury hospitalisation rates in Canadian jurisdictions: analyses examining associations with helmet legislation and mode share. BMJ Open 5:e008052, 2015

72. Thompson DC, Rivara FP, Thompson R: Helmets for preventing head and facial injuries in bicyclists. Cochrane Database Syst Rev (2):CD001855, 2000

73. Tsai MC, Hemenway D: Effect of the mandatory helmet law in Taiwan. Inj Prev 5:290-291, 1999

74. Vulcan AP, Cameron MH, Watson WL: Mandatory bicycle helmet use: experience in Victoria, Australia. World J Surg 16:389-397, 1992

75. Weiss H, Agimi Y, Steiner C: Youth motorcycle-related brain injury by state helmet law type: United States, 2005-2007. Pediatrics 126:1149-1155, 2010

76. Wesson DE, Stephens D, Lam K, Parsons D, Spence L, Parkin PC: Trends in pediatric and adult bicycling deaths before and after passage of a bicycle helmet law. Pediatrics 122:605-610, 2008

77. WHO: Motorcycle helmet laws and helmet standard. WHO. int (https://www.who.int/gho/road_safety/legislation/ situation_trends_motorcycle_helmet/en/) [Accessed October 25, 2019]

78. Williams C, Weston R, Feinglass J, Crandall M: Pediatric bicycle helmet legislation and crash-related traumatic brain injury in Illinois, 1999-2009. J Surg Res 222:231-237, 2018

79. Zamani-Alavijeh F, Bazargan M, Shafiei A, Bazargan-Hejazi $\mathrm{S}$ : The frequency and predictors of helmet use among Iranian motorcyclists: a quantitative and qualitative study. Accid Anal Prev 43:1562-1569, 2011

80. Zhang J, Norton R, Tang KC, Lo SK, Jiatong Z, Wenkui G: Motorcycle ownership and injury in China. Inj Control Saf Promot 11:159-163, 2004

\section{Disclosures}

The authors report no conflict of interest concerning the materials or methods used in this study or the findings specified in this paper.

\section{Author Contributions}

Conception and design: Lam, Du, LoPresti. Acquisition of data: Lam, Du, LoPresti. Analysis and interpretation of data: all authors. Drafting the article: all authors. Critically revising the article: all authors. Reviewed submitted version of manuscript: all authors. Approved the final version of the manuscript on behalf of all authors: Lam. Study supervision: Lam.

\section{Supplemental Information \\ Current Affiliations}

Dr. García: Division of Pediatric Neurosurgery, Ann and Robert H. Lurie Children's Hospital of Chicago, IL.

\section{Correspondence}

Sandi Lam: Northwestern University Feinberg School of Medicine, Chicago, IL. sandilam@luriechildrens.org. 